\title{
"O pharmakon e a vida ou a vida pharmakon?": algumas reflexões sobre narrativas de consumo de psicofármacos no contexto universitário ${ }^{1}$
}

\author{
Esmael Alves de Oliveira ${ }^{2}$ \\ Universidade Federal da Grande Dourados
}

Resumo: No dia 27 de novembro de 2019, o Programa de Pós-Graduação em Antropologia Social da UFMT recebeu o professor Esmael Alves de Oliveira, como conferencista de encerramento do IV Colóquio de Antropologia, cuja apresentação publicamos a seguir. Esse artigo é resultado de uma pesquisa de pós-doutorado realizada junto ao Programa de Pós-Graduação em Antropologia Social da Universidade Federal do Rio Grande do Sul (PPGAS/UFRGS) e vinculada ao Núcleo de Pesquisa em Antropologia do Corpo e da Saúde (Nupacs). Ao tomar como base a narrativa de professores universitários e estudantes de pós-graduação de algumas universidades públicas que faziam uso de ansiolíticos e/ou antidepressivos, o intuito foi o de tentar compreender quais os sentidos atribuídos à experiência da medicalização, bem como o pano de fundo em que esta se desenrolava. A partir de um movimento reflexivo de desnaturalização, sustentado nos dados de campo, foi possível compreender o consumo de ansiolíticos e antidepressivos como uma experiência dos diferentes processos de subjetivação do mundo contemporâneo.

Palavras-chave: medicalização; psicofármacos; subjetivação; universidade.

\footnotetext{
${ }^{1}$ Agradeço aos docentes e discentes do Programa de Pós-Graduação em Antropologia Social da Universidade Federal de Mato Grosso (PPGAS/UFMT) pelo convite para proferir a conferência que deu origem a esta versão. Os inúmeros questionamentos que se seguiram foram fundamentais para meu retorno ao texto e para o desdobramento de questões antes não vislumbradas e/ou não amadurecidas. Agradeço ainda a colega Ceres Víctora pelas inúmeras trocas ao longo do pósdoutorado e pelos intensos e fecundos diálogos oportunizados junto aos pesquisadores e às pesquisadoras do Núcleo de Pesquisa em Antropologia do Corpo e da Saúde (NUPACS), vinculado ao Programa de Pós-Graduação em Antropologia Social da Universidade Federal do Rio Grande do Sul (PPGAS/UFRGS).

2 Professor adjunto, do curso de Ciências Sociais, do Programa de Pós-Graduação em Antropologia (PPGAnt) da Faculdade de Ciências Humanas da Universidade Federal da Grande Dourados (FCH/UFGD) e do Programa de PósGraduação em Antropologia Social da Universidade Federal de Mato Grosso do Sul (PPGAS/UFMS). Doutor em Antropologia Social pela Universidade Federal de Santa Catarina (UFSC, 2014), com pós-doutorado junto ao Núcleo de Pesquisa em Antropologia do Corpo e da Saúde (NUPACS/UFRGS, 2018).
} 


\title{
"Pharmakon and life or the pharmakon life?": some thoughts on narratives about the use of psychopharmacological drugs in higher education
}

\begin{abstract}
On November 27, 2019, the Post-Graduate Program in Social Anthropology at UFMT received Professor Esmael Alves de Oliveira, as closing lecturer at the IV Anthropology Colloquium, whose presentation we will publish next. This article is the result of a postdoctoral research carried out with the Postgraduate Program in Social Anthropology at the Federal University of Rio Grande do Sul (PPGAS / UFRGS) and linked to the Center for Research in Anthropology of the Body and Health (Nupacs). Based on the narrative of university professors and graduate students from some public universities that used anxiolytics and / or antidepressants, the aim was to try to understand the meanings attributed to the medicalization experience, as well as the background on which it was unfolding. From a reflexive denaturalization movement, supported by field data, it was possible to understand the consumption of anxiolytics and antidepressants as an experience of the different subjectivation processes of the contemporary world.
\end{abstract}

Keywords: medicalization; psychopharmacological drug; subjectivation; university.

\section{"Farmakon y vida $\dot{c}$ o vida farmakon?": algunas reflexiones sobre narrativas de consumo de psicofármacos en el contexto universitario}

\begin{abstract}
Resumen: El 27 de noviembre de 2019, el Programa de Postgrado en Antropología Social de la UFMT recibió al profesor Esmael Alves de Oliveira, como conferenciante de clausura del IV Coloquio de Antropología, cuya presentación publicaremos a continuación. Este artículo es el resultado de una investigación posdoctoral realizada con el Programa de Posgrado en Antropología Social de la Universidad Federal de Rio Grande do Sul (PPGAS / UFRGS) y vinculada al Centro de Investigación en Antropología del Cuerpo y Salud (Nupacs). Basado en la narrativa de profesores universitarios y estudiantes graduados de algunas universidades públicas que usaron ansiolíticos y / o antidepresivos, el objetivo era tratar de comprender los significados atribuidos a la experiencia de medicalización, así como el fondo sobre el que se estaba desarrollando. A partir de un movimiento reflexivo de desnaturalización, respaldado por datos de campo, fue posible entender el consumo de ansiolíticos y antidepresivos como una experiencia de los diferentes procesos de subjetivación del mundo contemporáneo.
\end{abstract}

Palabras clave: medicalización; psicotrópicos; subjetivación; universidad. 


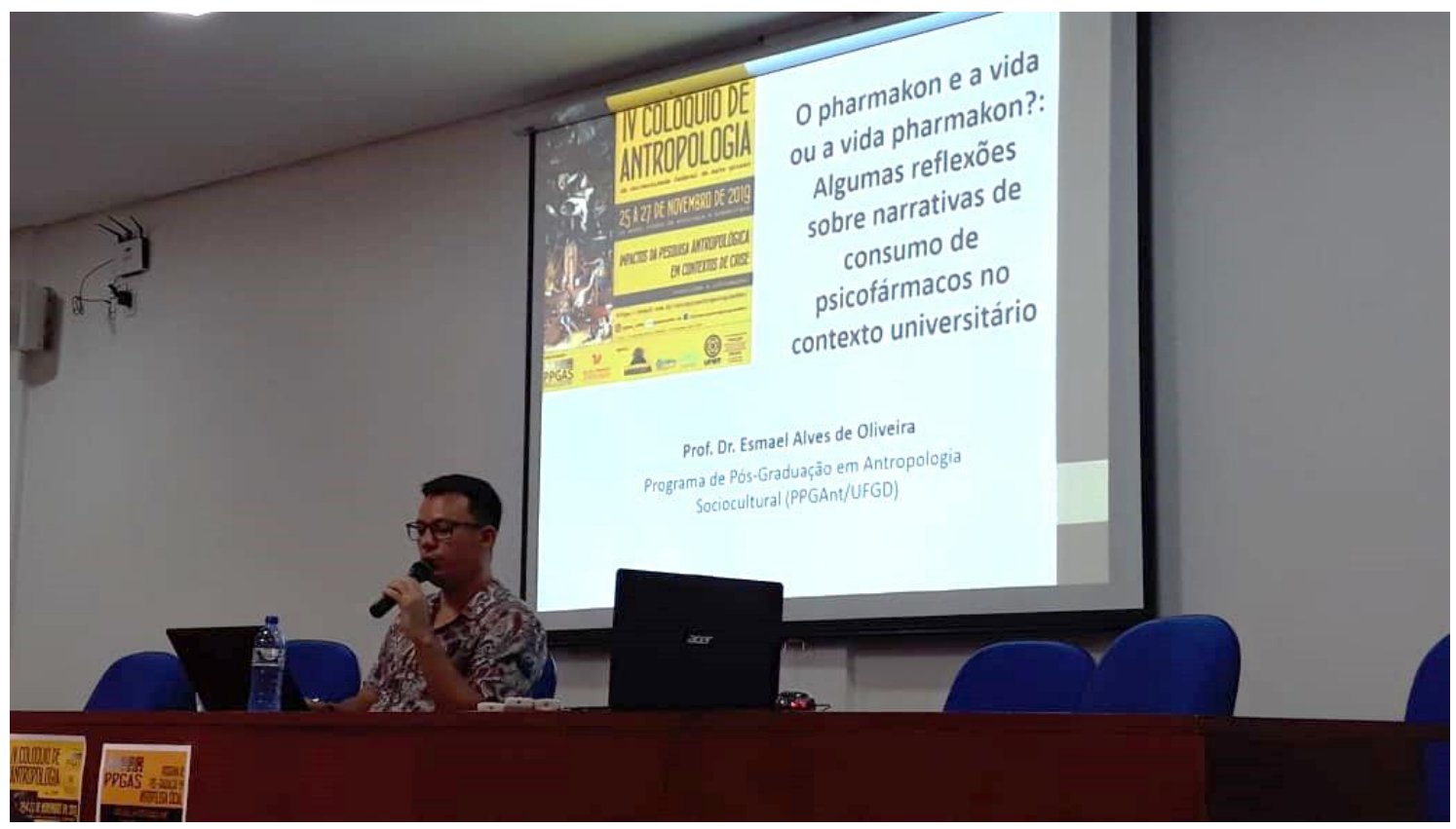

A contribuição da antropologia para a compreensão desta problemática consiste em mostrar como existem $n$ maneiras de utilizar as substâncias, em função de variáveis culturais sociológicas. Estas não só se somam, como complexificam as distinções que possam ser registradas ao nível de análise bioquímica (Gilberto Velho, 1980)

$\mathrm{E}$ sse artigo é resultado de uma pesquisa de pós-doutorado realizada junto ao Programa de Pós-Graduação em Antropologia Social da Universidade Federal do Rio Grande do Sul (PPGAS/UFRGS) e vinculada ao Núcleo de Pesquisa em Antropologia do Corpo e da Saúde (Nupacs). Ao tomar como base a narrativa de professores universitários e estudantes de pós-graduação de algumas universidades públicas que faziam uso de ansiolíticos e/ou antidepressivos, o intuito foi o de tentar compreender quais os sentidos atribuídos à experiência da medicalização, bem como o pano de fundo em que esta se desenrolava. Se diversas pesquisas têm apontado para o aumento no consumo de psicofármacos pela sociedade em geral, pouca atenção tem sido dada com relação a esse crescimento também no contexto universitário.

Em um cenário dominado pelo o que alguns autores têm chamado de farmaceuticalização da vida (ILLICH, 1975; BIEHL, 2005, 2008; ESHER e COUTINHO, 2017), a Antropologia tem cada vez mais problematizado as várias possibilidades de compreensão desse fenômeno. Assim, seja ao levantar questões de ordem ética, política e econômica que atravessam as intervenções da Big Pharma (PETRYNA, 2009), seja ao evidenciar a dimensão biopolítica das práticas de medicalização da vida (AZIZE, 2010; CAPONI, 2016) ou mesmo ao refletir sobre os processos de subjetivação e estratégias de agenciamento dos sujeitos 
"medicalizados" (BIEHL, 2005, 2008; FLEISCHER, 2012; ANDRADE e MALUF, 2016; OLIVEIRA e MARTINS, 2020) - aspectos que certamente não podem ser tomados isoladamente -, a perspectiva antropológica mais uma vez nos convida a uma compreensão desnaturalizada das práticas e das experiências dos sujeitos contemporâneos.

É a partir desse movimento de desnaturalização que busco compreender a experiência do consumo de psicofármacos. Para isso, tomei como norte algumas questões: afinal, sujeitos medicalizados ou relações medicalizadoras? Seria a noção ontologizante "sujeito medicalizado" suficiente para dar conta da experiência dos diferentes processos de subjetivação contemporâneos? São aspectos que busco explorar ao longo do presente artigo.

A pesquisa foi realizada no período de março de 2018 a março de 2019. Como metodologia, utilizei a proposta de bola de neve (BRAZ e HENNING, 2017), que consistiu em acionar alguns contatos pessoais e estes, por sua vez, indicavam-me outros interlocutores. Desse modo, à medida que a relação era estabelecida e os propósitos da pesquisa apresentados, logo fui remetido a uma série de colaboradores que talvez teria dificuldade para acessar de outra forma em decorrência da densidade do tema e das representações moralizantes que ainda o envolvem (VELHO, 2008). Ao todo, dialoguei com oito pessoas, sendo cinco professores universitários e três estudantes de pós-graduação de diferentes universidades públicas do Brasil. Todos os colaboradores foram selecionados a partir de dois critérios: sujeitos que iniciaram o consumo de ansiolíticos e/ou antidepressivos na universidade e que também eram altamente produtivos em termos acadêmicos (utilizei o Curriculum Lattes como base).

Ao me colocar disponível e atento aos modos como os diferentes sujeitos significavam a si mesmos, ao mesmo tempo em que enunciavam os contextos em que suas vivências e experiências em torno da medicalização eram forjadas, como afirmaria Geertz (2001), estava mais preocupado em "examinar dragões, não domesticá-los ou abominá-los, nem afogá-los em barris de teoria” (GEERTZ, 2001: 65).

\section{Diante de um cenário: uma vida medicalizada ou um contexto medicalizante?}

Até o momento, não existem dados sistematizados em escala nacional que apresentem um panorama dos níveis de adoecimento envolvendo docentes e discentes no ensino superior brasileiro. Os existentes ainda são escassos e fragmentados.

Com relação aos discentes, em pesquisa realizada em janeiro de 2018 pela Associação Nacional de Pós-Graduando (ANPG) ${ }^{3}$ junto a estudantes de pósgraduação da Universidade de Brasília, constatou-se um alto índice de sofrimento entre pós-graduandos. Contando com a participação de um total de 637 informantes, a pesquisa trouxe os seguintes dados: do total de entrevistados, 90\% relatam já ter experimentado um quadro de ansiedade; 71,6\%, desânimo; 63,1\%, irritabilidade; 59,1\%, energia, desejo e motivação reduzidos; 58,1\%, tristeza; 48,4\%, reclamações constantes; 48,4\%, oscilação do humor; 45,2\%, atenção e concentração reduzidas; 44,5\%, sonolência; $39,7 \%$, humor depressivo; $39,1 \%$, isolamento social; e $33,3 \%$, apatia. 
Dentre as principais razões apresentadas pelos estudantes destacam-se: falta de bolsa, estrutura, investimento (30\%); posicionamentos e relações com professores (20\%); posicionamentos e relações com orientadores (15\%); posicionamentos e relações com coordenadores (10\%); posicionamentos e relações com secretaria (10\%); disciplinas obrigatórias desnecessárias (10\%); e assunto da pesquisa (6\%).

Em relação aos docentes, os dados existentes também são alarmantes. Em pesquisa de 2014 divulgada pelo ANDES-SN e pela Associação dos Docentes da Universidade Federal do Pará (Adufpa Seção Sindical) e coordenada pelo médico e professor Jadir Campos, evidenciou-se que condições de trabalho adversas, oriundas da imposição do produtivismo acadêmico, podem levar docentes ao adoecimento mental. Segundo a pesquisa, entre 2006 a 2010, de todas as solicitações de afastamentos de professores do trabalho na UFPA, 14,13\% foram por questões relacionadas à saúde mental. ${ }^{4}$

Já em pesquisa realizada junto a 98 docentes da Universidade Federal do Espírito Santo que estavam vinculados a Programas de Pós-Graduação, Isabel Borsoi e Flavilio Pereira (2013) constataram a estreita relação entre produtividade e adoecimento docente. Segundo os autores, "os problemas que mais acometem os docentes são transtornos psicoemocionais, tais como depressão e ansiedade" (BORSOI; PEREIRA, 2013: 1215), evidenciados tanto por meio de relato dos professores e professoras quanto pelo aumento no número de afastamentos por motivo de doença. Conforme Borsoi e Pereira (2013: 1220),

\begin{abstract}
As porcentagens de professores que informam exercer as atividades descritas e fazer uso frequente de medicamentos, procurar ajuda médica e/ou psicológica e sofrer desconfortos físicos e/ou psíquicos nunca são inferiores a 40\%, chegando, em alguns casos, a atingir mais de $80 \%$.
\end{abstract}

Portanto, conforme os pesquisadores, "os dados apontam uma evidente relação entre excesso de trabalho e sofrimento e adoecimento entre os docentes" (BORSOI e PEREIRA, 2012: 1220).

O que esses dados revelam com relação ao fenômeno da medicalização? Estariam esses processos de adoecimento desvinculados de uma política de medicalização da vida? Especificamente em relação aos psicotrópicos, dados de 2015 revelam que: "em 2007, foram vendidas no Brasil 29 mil caixas de clonazepam, princípio ativo de medicamentos como o Rivotril. Hoje são mais de $23 \mathrm{mi}-$ lhões". 5

Em relação a esse dado, pelo menos duas constatações podem ser desveladas: primeiro, um aumento no consumo de psicotrópicos e, segundo, um crescimento expressivo de drogarias no Brasil. Conforme o Conselho Nacional de Saúde: "no Brasil existe uma farmácia (ou drogaria) para cada 3.300 habitantes e o país está entre os dez que mais consomem medicamentos no mundo, segundo dados do Conselho Federal de Farmácia”. ${ }^{6}$

Acreditamos que esses dados, tanto os que se referem aos altos índices de adoecimento de docentes e discentes das universidades brasileiras quanto ao aumento do consumo de psicofármacos, bem como à expansão do que tem sido chamado como Big Pharma, revelam a face de uma cultura da medicalização (AZIZE, 2002; PETRYNA, 2009). Esta precisa ser desnaturalizada e compreendida a partir de processos sociais, políticos, econômicos e ideológicos mais am-

4 Disponível em: http://portal.andes.org.br/imprensa/noticias/imp-ult-492400535.pdf. Acesso em: 01 mar. 2019.

5 Disponível em: https://www.cartacapital.com.br/saude/rivotril-a-droga-da-paz-quimica-3659/. Acesso em: 01 jun. 2018.

6 Disponível em: http://www.conselho.saude.gov.br/ultimas noticias/2005/medicamentos.htm. Acesso em: 01 jun. 2018. 
plos que buscam, por meio da psiquiatrização da vida, o estabelecimento de estratégias que resultem tanto na responsabilização individual dos sujeitos, ignorando arbitrariamente os dispositivos biopolíticos, quanto em sua exclusão social - gerando verdadeiras zonas de abandono (BIEHL, 2005; OLIVEIRA; MARTINS, 2020).

Portanto, entendemos o fenômeno da medicalização como um processo em que as dimensões da vida social e tudo aquilo que a atravessa e a constitui é reduzido à lógica biomédica, vinculando aquilo que não está adequado às normas sociais a uma suposta organicidade, que se expressaria na ideia de adoecimento psíquico do indivíduo, mas que é da ordem de uma produção social do sofrimento (VÍCTORA, 2011).

\section{Entre memórias, trajetórias e desabafos?}

Os relatos a seguir, obtidos e transcritos a partir de diálogos travados ao longo do meu trabalho de campo junto a professores universitários e a estudantes de pós-graduação, permitiram-me pensar sobre quais os elementos acionados em suas narrativas para significar suas trajetórias acadêmicas e os atravessamentos pela experiência da medicalização. Ao pedir que falassem sobre suas memórias dos tempos de estudantes e seu posterior ingresso na docência e/ou pós-graduação, desejava compreender como a universidade e sua dinâmica de funcionamento era retratada e, mais do que isso, se era possível vislumbrar alguma inter-relação entre a dinâmica de trabalho que caracteriza esse universo e o início do uso de psicotrópicos.

Dentre os vários aspectos a serem ressaltados, a questão temporal merece destaque. Em geral, são sujeitos que têm sua trajetória acadêmica iniciada a partir da década de 1990. Não é de se menosprezar o fato de que desse momento em diante novos corpos e subjetividades de docentes e discentes também são reconfigurados a partir da produção de medicamentos em escala cada vez mais globalizada, do crescimento do poderio econômico e político da indústria farmacêutica (que em relação aos psicofármacos já atuava desde a década de 50 do século $\mathrm{XX}$ ), da expansão e consolidação da psiquiatrização da vida a partir da contínua reformulação dos DSMs (RUSSO e VENÂNCIO, 2006; BIEHL, 2011; CAPONI, 2014, 2016), bem como das transformações pelas quais passaram e passam as políticas voltadas ao ensino superior no Brasil e no mundo (FREITAS, 2019).

A seguir, algumas narrativas ${ }^{8}$ que dão conta de algumas dessas transformações nos ajudam a compreender que os processos de adoecimento estão longe de se constituírem como uma questão de ordem individual e biológica. Antes, não podem ser desvinculados de discussões em torno de governo, mercados, sistemas e políticas de saúde, saberes biomédicos e psi, corpos e subjetividade(s), dentre outros (BIEHL, 2011; CAPONI, 2016).

Minha trajetória sempre esteve marcada por certo deslumbramento da vida acadêmica. Me recordo que, durante a graduação na década de 9o, ser professor universitário era algo que rendia bastante prestígio. Era raro ter aulas com um professor com doutorado (não sei se era algo particular da região onde me situava) $e$ quando se tinha aula com algum doutor era ocasião de orgulho. A impressão que tínhamos naquele momento era que o doutorado seria uma espécie de coroamento de

\footnotetext{
7 Por preocupações de ordem ética, combinei com os colaboradores e colaboradoras que suas identidades pessoais, institucionais e regionais seriam devidamente preservadas.

8 Pelo compromisso ético de não exposição, optei por não fazer referência a nenhuma informação pessoal dos interlocutores e interlocutoras de pesquisa. Além disso, interessava-me não a ideia de representatividade, mas a dimensão discursiva, suas redes de articulação e significação (GEERTZ, 2008).
} 
uma trajetória. Tanto é verdade que quando nossos mestres saíam para o doutorado, voltavam e permaneciam pouco tempo - logo depois se aposentavam. Quando olho para o que se tornou a universidade hoje, com todo seu carreirismo meritocrático, é algo insano.

Nasci na década de 9o, ingressei na universidade em 2006. Na época tinha 16 anos. Venho de uma família de classe média alta e havia muita expectativa de que eu fosse bem-sucedido como grande parte de meus familiares. O desejo de meus pais na época era que eu fosse estudar fora, mas eu não desejava. Acabei ingressando numa universidade renomada do Sudeste. Lá fiz graduação, mestrado e doutorado em História - para decepção dos meus pais, que desejavam ou Medicina ou Direito. Essa experiência foi marcada por muita cobrança. Lembro de alguns professores que nos diziam: 'vocês precisam ser os melhores, nada menos do que isso. Afinal, vocês ingressaram nessa instituição'. Isso gerava um ambiente competitivo. Havia uma aura de encantamento com os professores renomados. O que posso dizer é que isso teve um preço. Ser o melhor no mundo acadêmico custa caro - e quem dera estivesse falando em termos econômicos! Ao longo de minha trajetória acadêmica não foram poucos colegas que surtaram porque não deram conta do sistema meritocrático. Eu sobrevivi, mas não posso dizer que sem marcas.

Sou professora universitária há pouco tempo, se comparada com outros colegas. Ingressei no magistério superior em 2008, na época em que os concursos ainda contemplavam vagas para mestres. Posso dizer que sou filha de uma universidade em transição. A formação que tive ao longo da década de 9o, quando ainda estava na graduação (formei em 20oo), e a realidade que vivenciei no doutorado, quando já era professora universitária, é completamente diferente. A impressão que tenho é que houve uma mudança radical entre um modelo que privilegiava o tempo e o amadurecimento das ideias e uma época da agilidade, eficiência e produtividade. Acho muito simbólico o fato de alguns colegas receberem uma bolsa que tem justamente esse título: produtividade.

\begin{abstract}
Ingressei no mestrado em 2016. Nossa, que loucura! Na verdade, quando via meus professores lamentando em sala de aula ou pelos corredores sobre a sobrecarga de trabalho, não fazia ideia de como era verdadeiro. Enquanto aluno de graduação, posso dizer que aproveitei muito: as festas, os namoros, as redes de amizade. Confesso que nem sempre estava no curso de corpo inteiro. Se você pegar meu histórico vai perceber que eu fui um aluno displicente. Mas não me arrependo. No mestrado quis sair da minha cidade onde fiz faculdade e ir para outra. A ideia era ter mais autonomia. Meus pais (ambos do mundo do Direito) queriam me controlar e dizer o que eu deveria fazer. Não queria que os planos deles se tornassem os meus. Quando passei na seleção, num primeiro momento, não acreditei, embora tivesse me dedicado muito. Queria muito ser aprovado. Eu só não sabia o que estava desejando. Estar no mestrado tem sido difícil. É uma rotina praticamente militar: grupo de pesquisa, laboratório, estudar muitas coisas em outros idiomas. Às vezes me sinto um impostor.
\end{abstract}

Há na fala dos/as interlocutores/as uma percepção de que mudanças sociais teriam ocorrido ao longo da década de 1990 e se acentuado ao longo de 2000, responsáveis por produzir uma experiência de universidade mais marcada por um produtivismo. Em cena se encontram duas questões: primeiro, uma mudança no modelo de universidade; segundo e, consequentemente, uma questão de ordem geracional. Se, para a geração cuja formação se deu ao longo da década de 1990, estar na pós-graduação significou o "coroamento" de uma trajetória, as gerações mais novas, da década de 2000, passam a vivenciá-la como algo "indispensável”. Tais mudanças, de nível político-econômico-institucional, foram responsáveis por produzirem determinadas formas de subjetivação anteriormente inexistentes.

Assim, os projetos de vida que vislumbravam a vida acadêmica como uma escolha que produziria realização, aos poucos, quando acessada, passa a ser atravessada também por dissabores. O ritmo acelerado e a quantidade de atribuições e responsabilidades são apresentados como os principais fatores. Para além disso, há uma expectativa social e institucionalmente produzida de que o que se faz nunca seria o suficiente. Importa mencionar ainda que, durante o 
trabalho de campo, não foram poucas as vezes em que a categoria "síndrome do impostor" veio à tona na fala de alguns/algumas interlocutores/as.

O que seria essa "síndrome do impostor"? Trata-se de uma insatisfação assumida pelo sujeito face ao próprio desempenho diante de demandas que lhe são apresentadas socialmente (no caso, institucionalmente). Ou seja, há uma série de expectativas a serem atendidas, que se espera que sejam executadas com brilhantismo e que, no caso da universidade, estão, em geral, revestidas de uma métrica que envolve tempo (cumprimento de prazos), desempenho (trabalhos com "nível de excelência") e reconhecimento da comunidade científica (manifesto seja em aceites de eventos de grande "impacto", seja na publicação de periódicos "bem qualificados"). Tais métricas são nuançadas por redes complexas de poder, conhecimento e capital (econômico e político) (PRECIADO, 2018), nem sempre evidenciadas, mas que variam de acordo com os contextos em que se dão.

Com relação a esse ponto, basta lembrar as clivagens entre universidades centrais e periféricas que refletem outra dicotomia: programas de "excelência" (aqueles cuja avalição pela CAPES varia de 6 a 7 e que são caracterizados pela alta produtividade do corpo docente) e programas regulares (de métrica 3 a 5 e cuja baixa produtividade tem grande impacto).

Nesse quadro, professores, professoras, pós-graduandos e pós-graduandas que estão vinculados às universidades e programas considerados de excelência apresentam relatos recorrentes de sofrimento social. Isso não quer dizer que em outros contextos (fora dessas adjetivações) não tenham se verificado relatos de uso de psicofármacos. O que cabe considerar é que há uma recorrência na afirmação de que "chegou-se num certo limite" em que não se consegue "dar conta" e em que se "precisa de ajuda". A díade: situação (p. e. prazos, eventos) e relação (docente $v s$ discente; discente $v s$ docente; docente $v s$ docente; chefias $v s$ docentes e discentes) aparece com relevo.

O que foi possível observar ao longo da pesquisa é que, de maneira geral, há uma grande percepção de que essas relações são adoecedoras. Contudo, apesar do reconhecimento individual e coletivo do impacto das "métricas" na saúde mental, institucionalmente, não se questiona sua legitimidade. Ou seja, se docentes e discentes falam sem embaraços sobre suas dificuldades para atender as demandas e expectativas do "sistema", os mecanismos institucionais para sua revisão ou atenuação têm se mostrado inexistentes. Aos que conseguem, há muito custo e não sem um preço (segundo alguns/algumas deles/as, "alto") para se satisfazerem as métricas produtivistas, o "reconhecimento" e as "recompensas" (p. e. as bolsas produtividade). Pelo contrário, aos "fracassados" sobram os estigmas advindos do adoecimento ("não deram conta") e, por vezes, seu consequente afastamento das funções acadêmicas (ou até mesmo seu desligamento).

Portanto, se em alguns casos há o reconhecimento de que angústias e dificuldades sempre os acompanharam, é a dinâmica de funcionamento da universidade que se constitui como o grande disparador do recurso à medicalização. Assim, retira-se de cena a engrenagem produtora de adoecimento e, para mantê-la intocada, apela-se para a ordem de uma "clínica" dos sintomas e dos diagnósticos. Como esclarece Deleuze (1997: 09): “[...] quando o delírio recai no estado clínico, as palavras em nada mais desembocam, já não se ouve nem se vê coisa alguma através delas, exceto uma noite que perdeu sua história, suas cores e seus cantos". 


\title{
Entre exigências, expectativas e "uns comprimidos para dar conta"
}

\author{
Seguem outros fragmentos de relatos dos/das interlocutores/as que me aju- \\ daram a pensar acerca dos processos de subjetivação que são produzidos e expe- \\ rimentados no consumo de psicofármacos. Se, por um lado, a partir do disposi- \\ tivo psi, a presença de um laudo parece ser "suficiente" para "atestar" a pretensa \\ condição de "doente" do sujeito, de outro, o diagnóstico não parece ser suficien- \\ te para explicar os mecanismos que fazem com que sejam produzidas formas \\ singulares de significação dessa experiência.
}

\begin{abstract}
Meu noivo é estudante de Medicina, está na fase do internato. Temos uma vida louca nós dois. Ele, com os plantões do último ano do curso, eu, com a pesquisa do mestrado. Apesar da loucura compartilhada em termos de rotina, às vezes penso que ele tem mais qualidade de vida do que eu. Desde que ingressei na pós, tenho sido tomada por várias crises de insônia. A rotina de cobranças do orientador, os prazos, a exigência de publicação é muito exaustiva. às vezes acho que vou sucumbir. Nesse inferno astral foram vários os momentos que fiquei no limite. Nessa rotina, só uns comprimidos para dar conta. Até parece que não somos humanos, que não temos vida.
\end{abstract}

Como já lhe disse: estar nesse lugar de professora universitária não é simples. Já pensei várias vezes em mudar de profissão. Atualmente recebo uma bolsa produtividade que, entre outras coisas, me "premiou" com o uso de ansiolítico e antidepressivo. Tudo começou com uma crise de insônia, aos poucos foi piorando. Já não conseguia dormir. No outro dia, estava na sala de aula ou em alguma reunião como um zumbi. Sempre fui muito resiste a medicamentos, mas não tive como não recorrer. Logo depois tive uma crise de pânico, não conseguia nem mais sair de casa. De repente o sonho de ser professora universitária se tornou um pesadelo. Estava doente. E onde ficam os projetos? Os sonhos? Os risos? Aos poucos o que era sonho vira pesadelo.

Sempre fui muito ansioso, desde criança. Mas era uma época em que nem se falava de ansiedade. Me chamavam de pica pau, pois eu não parava quieto. Não tenho dúvida que se crescesse hoje seria diagnosticado de hiperativo. Mas, enfim, nunca significou um problema pra mim. Foi meu ingresso no magistério superior que representou uma guinada. Uma rotina que posso dizer por experiência própria: enlouquecedora. Projetos de pesquisa, orientar estudantes de graduação e pósgraduação, participar de comissões, dar parecer, ministrar aulas, escrever artigos. Não é à toa que tem se ouvido a expressão: alimentar o cão de lattes. A que custo? Só o diazepam para dizer.

Sou egressa do curso de Psicologia e minha experiência de graduação não foi diferente da experiência que tenho como aluna da pós. Lembro que desde o primeiro semestre do curso prevalecia entre nós uma dada competitividade que era concretizada no IDA (Índice de Desempenho Acadêmico). Acho até que era uma política do curso porque, pelo que me lembro, a escolha pelos estágios específicos era baseada no IDA, ou seja, os alunos com o melhor desempenho tinham as maiores chances de realizar o estágio do seu interesse - que em geral eram os mais concorridos. Particularmente, não sei se isso mudou quando ingressei na pós. Talvez a roupagem tenha mudado, mas o conteúdo permanece o mesmo. Aqui prevalece uma política de concorrência entre os mestrandos de quem consegue publicar mais e uma dada vaidade quando você é orientado por um professor que tem um curriculum lattes "inflado". Os relatos de adoecimentos não são incomuns. Eu mesma faço terapia e tenho consumido antidepressivos desde que entrei na universidade. Durante a graduação não era incomum saber de tentativas de suicídio dentro do próprio curso de Psicologia. Isso me inquietava: o que está acontecendo? Será que não tem alguma coisa errada? Como assim um curso que vai cuidar de pessoas adoecidas e que tem produzido adoecimento? Hoje na pós eu já não sei se isso é uma exclusividade da graduação e nem mesmo só da Psicologia. 


\section{O pharmakon e a vida ou a "vida pharmakon" 10 ?}

Todas as narrativas expostas evidenciam que, apesar das trajetórias singulares dos sujeitos, a experiência universitária os marcou de um modo que suas experiências se tornam em alguma medida compartilhadas (VELHO, 2008). São muitos os atravessamentos que não podemos desconsiderar: classe, região, formação, gênero etc., mas, apesar deles, há algo em comum: em algum momento, seja na condição de docente, seja na de discente, a universidade se tornou um ambiente adoecedor.

Nas narrativas, são comuns categorias do universo psi (crise, síndrome, classificação). Acredito que elas, concretizadas no diagnóstico, operam em um duplo movimento de negação e afirmação, tanto uma posicionalidade assimétrica (incapacidade, limitação, falta, doente) quanto a elaboração de uma narrativa sobre si, sobre suas dificuldades e sofrimentos. É, sobretudo, este último aspecto que me interessa. Portanto, o grande desafio é de percebê-las não enquanto diagnóstico ou sintoma, mas enquanto sujeitos que conseguem, apesar deles, produzir formas próprias de narrar, experimentar e lidar com suas aflições e, dessa forma, reinventarem-se (RODRIGUES, 2020). Essas narrativas e trajetórias revelam modos muito concretos de como os processos de adoecimento são produzidos, negociados e agenciados, tanto individual como coletivamente, e cuja lógica biofarmacológica está longe de ter a última palavra (BIEHL, 2008; OLIVEIRA; MARTINS, 2020).

Diferentes autores têm chamado atenção para a importância de considerarmos os processos de adoecimento, de modo geral, e, no contexto universitário, de modo particular, para além de uma dimensão meramente individual, subjetiva e orgânica (LANGDON, 1994; 2005; BORSOI; PEREIRA, 2013; FREITAS, 2019). Os relatos nos permitem inferir que nenhum sofrimento, por mais que seja vivenciado na dimensão pessoal, está desvinculado de uma produção social e coletiva (VÍCTORA, 2011).

O pharmakon, no sentido grego do termo, entendido como uma substância que tanto pode curar quanto matar, aqui é usado como metáfora para pensarmos as nuances e ambiguidades de contextos que produzem relações adoecidas e adoecedoras.

Em sua clássica etnografia sobre o consumo de tóxicos em camadas médias cariocas, Gilberto Velho (2008) apontava para os limites da categoria "viciado". Para ele, "esse universo [...] está longe de ser homogêneo ou monolítico" (VELHO, 2008: 15). De acordo com o autor, "as diferenças internas, em termos do tipo de tóxico utilizado, faixa etária, características de estrato social, vão marcar, em muitas situações, fronteiras bastante nítidas" (2008: 15).

Do mesmo modo, Ana Paula Andrade e Sonia Maluf (2016), tomando como marco a Política Nacional de Saúde Mental (BRASIL, 2001), apontam que, com relação ao movimento de reforma psiquiátrica no Brasil, podemos pensar em avanços e conquistas em termos de desistinsticionalização, mas, ao mesmo tempo, na pouca atenção que tem sido dada aos usuários dos serviços de saúde mental como agentes ativos do processo. Assim, as autoras, a partir de trabalho

10 Alerto para o caráter analítico da categoria "vida pharmakon”. Nesse sentido, não ignoro as possibilidades e contradições que os interlocutores e interlocutoras apresentam em relação ao consumo de psicofármacos. O termo é aqui utilizado no sentido de um conjunto de crenças, valores, estilos de vida e visões de mundo socialmente compartilhadas (VELHO, 1999, 2008) e ao mesmo tempo aponta para o fato de que mesmo atitudes que nos são comunicadas como decisões individuais podem ter sido construídas coletivamente (FLEISCHER, 2012). 
de campo realizado junto a usuários dos serviços de saúde mental, questionam a categoria universalizante e homogeneizante de "usuário".

Em meu entender, é esse mesmo processo de ontologização da experiência que pode ser constatado na categoria "sujeitos medicalizados" e que, no entanto, não é capaz de dar conta dessas experiências e trajetórias múltiplas. Ou seja, docentes e discentes, ainda que atravessados por trajetórias, experiências e expectativas distintas em seus percursos acadêmicos, são "facilmente" encapsulados em categorias psiquiatrizantes que pouco ou nada dizem sobre o conjunto mais amplo das relações que se produzem no interior da universidade.

Do mesmo modo que a Antropologia da saúde tem destacado o fato de que a doença não é uma essência (o doente), mas uma experiência (estar doente) (LANGDON, 1994, 2005; SARTI, 2010), o desafio é o de pensarmos que uma possível identidade atrelada ao sujeito adoecido e que aponte para uma condição ontológica (p. e. o doente, o medicalizado) acaba por obscurecer a dimensão contextual (portanto social, simbólica, política, econômica) que o enreda. Portanto, do mesmo modo que na pesquisa de Velho (2008) a categoria "viciado" e, na pesquisa de Andrade e Maluf (2016), a noção de "usuário" pouco davam conta dos múltiplos sentidos acionados e agenciados pelos diferentes sujeitos, a categoria "medicalizado" também resulta redutora.

Assim, as narrativas elaboradas pelos sujeitos em cena falam de uma condição de irredutibilidade dos fenômenos e experiências humanas à lógica taxonômica medicalizadora. A partir da constatação da precariedade das categorias ontologizantes, ponderam Andrade e Maluf (2016: 255):

\begin{abstract}
Tal precariedade apareceu com vigor nos dados de campo, o que nos fez pensar tais categorias como variáveis, uma vez que reconhecemos uma circularidade de posições ocupadas pelo mesmo sujeito. Aquele/a que era familiar também poderia ser alguém com diagnóstico, usuário/a do sistema de atenção à saúde; aquele/a que era diagnosticado e usuário poderia ser também familiar e, algumas vezes, aquele/a que era trabalhador/a poderia ter recebido um diagnóstico como ser também familiar. Várias combinações acabaram aparecendo, o que nos alertava para a intercambialidade de posições.
\end{abstract}

Acredito que a clareza presente nas narrativas dos/as entrevistados/as quanto aos processos que foram responsáveis por conduzi-los e conduzi-las à medicalização não pode ser devidamente compreendida fora de um contexto social e relacional mais amplo e que as taxonomias patologizantes estão longe de dar conta. Ao contrário, no limite, uma perspectiva meramente nosológica tende a responsabilizar e culpabilizar, por meio do processo de individualização dos processos de adoecimento, os sujeitos e seus processos de padecimento (FLEISCHER, 2018).

Em trabalho recente, Rafael Freitas (2019) alerta para a importância de pensarmos sobre os processos de adoecimento no contexto universitário como produto de relações históricas e sociais mais amplas. Segundo ele, há a necessidade de que entendamos o sofrimento "muito mais enquanto um tópico da ordem das relações sociais e das estruturas nas quais os estudantes [e professores] estão inseridos do que uma questão de ordem individual” (FREITAS, 2019: 1, acréscimo meu). Para o pesquisador, não podemos ignorar o intenso processo de mercantilização do ensino superior que cada vez mais tem sido inserido em uma lógica produtivista em que prevalece uma política de "monetarização da universidade" (FREITAS, 2019: 2).

Além disso, a relação estabelecida com medicamentos não é experimentada da mesma forma nem compreendida do mesmo modo por todos/as que o utilizam como recurso (VELHO, 2008). Ainda que essa pesquisa tenha como foto 
pessoas que utilizam ansiolíticos e antidepressivos, importa mencionar que outras pesquisas têm destacado como alguns medicamentos psicotrópicos têm um forte apelo social e podem servir como "estimulantes". Eleonora Bachi Coelho e Ondina Fachel Leal (2015), por exemplo, investigaram como o metilfenidato, popularmente conhecido como pílula da inteligência, tem sido amplamente utilizado por setores da sociedade brasileira, sobretudo jovens, com o intuito de melhorarem seus desempenhos, ou seja, "aprimorar" suas performances.

Vale lembrar que o metilfenidado ou ritalina (da família das anfetaminas), enquanto psicoestimulante, é prescrito por médicos e psiquiatras principalmente em casos de dignóstico de déficit de atenção e hiperatividade. Ao contrário do que ditam as indicações psi, no trabalho de campo realizado pelas autoras, chegou-se à constatação: "todos os entrevistados relatam dificuldades para desempenhar atividades de estudos de acordo com suas expectativas, necessidades e aquilo que entendem ser a demanda social de desempenho" (COELHO e LEAL, 2015: 167, grifo meu).

No circuito mapeado por Coelho e Leal (2015), fica evidente que, por parte dos consumidores de ritalina, há uma necessidade de responder a demandas socialmente impostas e que se expressam no desejo de satisfação de expectativas, sobretudo, no que se refere a desempenho. Essa busca por eficácia, por responsividade, rendimento, é acionada diante de contextos relacionais em que prevalece a necessidade de ser competitivo, de ter excelência e de não falhar.

Elas ressaltam que o consumo de ritalina "constitui a resposta para a demanda de uma sociedade competitiva e individualista" (COELHO e LEAL, 2015: 170). Contudo, todas essas demandas socialmente impostas são assumidas como da ordem da individualidade. Como afirmado anteriormente, em cena, vigora uma noção de sujeito incapaz, deficitário, ineficaz. Portanto, qualquer estratégia que possibilite um hiper rendimento é algo a ser acionado. Conforme aponta Freitas (2019: 53), "enquanto a redução de produtividade no caso de pessoas que experimentam episódios depressivos é rapidamente entendida, pelos próprios estudantes e por terceiros, como um adoecimento, no caso da adesão a uma hiper produtividade, isso é recebido como um elogio". Ainda segundo o autor, "o esforço é um símbolo privilegiado na valoração das relações sociais em um ambiente corporativo, do qual a universidade não escapa" (FREITAS, 2019: 70).

No caso de meus interlocutores e interlocutoras, é relatado que o recurso a ansiolíticos e antidepressivos surge como alternativa em "momentos limites", marcados por sentimentos como: "não dar conta", "não conseguir dormir", "estar entrando em colapso", "estar no piloto automático" etc. Aparece também a narrativa de um momento "gatilho", em que eles e elas se dão conta de que precisam de "ajuda”. É como se demandas sociais concretas (prazos, relatórios, comissões, orientações, artigos, teses e dissertações etc.) e difíceis de serem cumpridas - dada sua quantidade e frequência, passassem a ser "internalizadas" e sintomatizadas. O que é da ordem institucional e coletiva aos poucos se estabelece como uma questão de ordem individual: "o sujeito que não dá conta".

Importa mencionar que é a consciência da existência de uma relação de trabalho e estudo com exigências "sobre-humanas" (portanto, adoecedoras), a qual não mais se consegue responder, que possibilita que o sofrimento não se torne alienante, individualizado e incontornável. 


\section{Algumas (in)conclusões}

A partir do exposto, ficou evidente que os mecanismos de apagamento das condições sociais mais amplas que produzem os processos de adoecimento são perversos. Eles, como uma engrenagem de produção de sujeitos adoecidos, tiram de cena a "peça estragada", sem alterar ou comprometer o funcionamento da lógica produtivista.

Portanto, pensar em termos de uma vida pharmakon não significa naturalizar a experiência da medicalização contemporânea. Antes, implica compreender que os sujeitos buscam diferentes estratégias e acionam distintos recursos para lidar com as situações-limite histórica e socialmente produzidas. Nesse sentido, ao longo do desenvolvimento da pesquisa, ficou evidente que há, por parte dos sujeitos ${ }^{11}$, o reconhecimento das condições que produzem seu(s) adoecimento(s). Talvez seja por isso que o medicamento apareça como último recurso e nunca como um fim em si mesmo.

Os medicamentos entram em cena quando se percebe que o reconhecimento das condições de existência já não é suficiente para evitar a insônia, a depressão, as crises de pânico, os pensamentos suicidas etc. (FLEISCHER, 2012). Apesar disso, o aparente "rendimento", "captura", é vivenciado como uma fase de transição ("não pretendo ficar dependente"), como uma oportunidade de avaliação do estilo de vida ("que vida era essa que eu estava levando e que quase me jogou no fundo do poço?") e, mais do que isso, como a manifestação do desejo de que é possível atuar sobre as condições de sofrimento socialmente produzidas e impostas ("quando for professor não quero fazer o que meus professores fizeram comigo"; "hoje vejo minha atuação na universidade de outra forma. Quando você chega no fundo do poço e retorna, volta com uma pergunta: o que vale a pena e o que não vale?; "O que é mesmo ser produtiva? Quem vai dizer de minhas capacidades? Um sistema de registro de informações chamado Lattes?”).

Assim, por mais que tais experiências se deem a partir de um conjunto concreto de situações e relações mais amplas, as produções de sentidos e os agenciamentos em torno da medicalização falam de caminhos possíveis e nunca previamente determinados (FLEISCHER, 2018). Para aqueles críticos que argumentam que em algum momento há a utilização da categoria medicalizado como estratégia para a não autorresponsabilização, auto-implicação e comprometimento pessoal face às demandas institucionais, ou seja, como "desculpas" que atuariam como uma espécie de "muleta", o que posso afirmar é que não foi o que pude experimentar em campo.

Pelo contrário, a compreensão das condições de trabalho, a utilização do processo psicoterapêutico como estratégia primária e auxiliar, o recurso ao medicamento como última alternativa e o desejo de que em algum momento se possa deixar de utilizá-los apontam para um processo evidente de engajamento ativo e criativo nos processos e formas de significação do(s) self(s) e, mais do que isso, de sua contínua invenção (ROSE, 2011). Não por acaso, as múltiplas elaborações em torno do consumo, a negociação em torno das dosagens, os diferentes recursos utilizados e mobilizados para dar sentido às experiências de sofrimento.

\footnotetext{
11 Não podemos desconsiderar, contudo, a importância do elemento classe na trajetória desses docentes e discentes. Todos/as eles/as, além de terem consciência das condições que os/as conduziram ao adoecimento, conseguiam (em decorrência do lugar privilegiado que ocupam), para além da medicação, recorrer a outros meios, como o psicoterapêutico, relativizando assim a medicalização como um fim em si mesmo. Pesquisas futuras podem contribuir com o fim de apontar como os marcadores sociais também influenciam os processos de medicalização da vida.
} 
Por fim, cabe mencionar que pensar em um processo de subjetivação contemporânea que passa pelo consumo de medicamentos implica reconhecer que estamos inseridos em uma sociedade (portanto, em um conjunto complexo de relações) em que predomina um esvaziamento de significados, cuja medicalização da vida aparece como um recurso incontornável.

Ao mesmo tempo, esse caráter de obviedade aos poucos mostra-se frágil e precário se consideramos que estamos diante de experiências relacionalmente produzidas e negociadas. Parafreasendo Vargas (2006), mais do que perguntar "por que as pessoas usam psicofármacos?" e "qual o significado do de seu consumo?", o objetivo do presente trabalho foi o de estar atento à(s) experiência(s) que os/as usuários/as produzem e realizam.

Nesse enquadre em que interagem contextos, relações, subjetividades e psicofármacos, emerge a produção de sujeitos que demonstram uma agência muito criativa no trato dos corpos individuais, sociais e políticos (FLEISCHER, 2012, 2018).

\section{Referências}

ANDRADE, Ana Paula Müller de; MALUF, Sônia Weidner. Sujeitos e(m) experiências: estratégias micropolíticas no contexto da reforma psiquiátrica no Brasil. Physis - Revista de Saúde Coletiva, 26 (1): 251-270, 2016.

AZIZE, Rogerio Lopes. A química da qualidade de vida: um olhar antropológico sobre o uso de medicamentos e saúde em classes médias urbanas brasileiras. Dissertação (Mestrado) - Programa de Pós-Graduação em Antropologia Social. Florianópolis: Universidade Federal de Santa Catarina, 2002.

BRAZ, Camilo; HENNING, Carlos Eduardo (orgs.). Gênero, sexualidade e saúde: diálogos latino-americanos. Goiânia: Editora da Imprensa Universitária, 2017.

BRASIL. Política Nacional de Saúde Mental. Brasília: Ministério da Saúde, 2001.

BIEHL, João. Antropologia no campo da saúde global. Horizontes Antropológicos, 17 (35): 227-256, 2011.

BIEHL, João. Antropologia do devir: psicofármacos - abandono social - desejo. Revista de Antropologia, 51 (2): 413-449, 2008.

BIEHL, J. Vita: life in a zone of social abandonment. Berkeley: University of California Press, 2005.

BORSOI, Izabel Ferreira; PEREIRA, Flavilio Silva. Professores do ensino público superior: produtividade, produtivismo e adoecimento. Universitas Psychologica, 12 (4): 1211-1233, 2013.

CAPONI, Sandra. "Classificar e medicar: a gestão biopolítica dos sofrimentos psíquicos”. In: CAPONI, Sandra et al. (orgs.). A medicalização da vida como estratégia biopolítica. 1 $^{\mathrm{a}}$. reimpressão. São Paulo: Editora LiberArs, 2016. pp. 97-114. 
CAPONI, Sandra. O DSM-V como dispositivo de segurança. Physis - Revista de Saúde Coletiva, 24 (3): 741-763, 2014.

COELHO, Eleonora Bachi; LEAL, Ondina Fachel. "Fabricando um corpo sem limites: a busca pelo sucesso profissional e o consumo de metilfenidato". In: MCCALLUM, Cecilia Anne; ROHDEN, Fabíola (orgs.). Corpo e saúde na mira da Antropologia. Salvador: EDUFBA e ABA, 2015 p pp. 155-175.

DELEUZE, Gilles. Crítica e clínica. São Paulo: Ed. 34, 1997.

ESHER, Angela; COUTINHO, Tiago. Uso racional de medicamentos, farmaceuticalização e usos do metilfenidato. Ciência e Saúde Coletiva, 22 (8): 2571-2580, 2017.

FLEISCHER, Soraya. 2018. Descontrolada: uma etnografia dos problemas de pressão. São Carlos: EdUFSCar, 2018.

FLEISCHER, Soraya. Uso e circulação de medicamentos em um bairro popular urbano na Ceilândia, DF. Saúde e Sociedade, 21 (2): 410-423, 2012.

FREITAS, Rafael de Mesquita Ferreira. Uma multidão de pessoas sós: narrativas de adoecimento e acolhimento na universidade, a partir de grupos terapêuticos. 2019. Dissertação (Mestrado) - Programa de Pós-Graduação em Antropologia. Fortaleza: Universidade Federal do Ceará, 2019.

GEERTZ, Clifford. A interpretação das culturas. Rio de Janeiro: LCT, 2008.

GEERTZ, Clifford. Nova luz sobre a antropologia. Rio de Janeiro: Jorge Zahar, 2001.

LANGDON, Esther Jean. "A doença como experiência: a construção da doença e seu desafio para a prática médica”. In: BARUZZI, Rogerio G.; JUNQUEIRA, Carmen (orgs.). Parque Indígena do Xingu: saúde, cultura e história. São Paulo: Terra Virgem, 2005. pp. 115-133.

LANGDON, Esther Jean. "Representações de doença e itinerário terapêutico dos Siona da Amazônia colombiana”. In: SANTOS, Ricardo V.; COIMBRA JR, Carlos E. A. (orgs.). Saúde e povos indígenas. Rio de Janeiro: Editora Fiocruz, 1994. pp. 115-42.

OLIVEIRA, Esmael Alves de; MARTINS, Catia Paranhos. Sobre práticas de medicalização e "loucura": algumas reflexões in(disciplinadas). Revista Psicologia e Saúde, 12: 101-113, 2020.

PETRYNA, A. When experiments travel: clinical trials and the global search for human subjects. Princeton: Princeton University Press, 2009.

PRECIADO, Paul Beatriz. Testo junkie: sexo, drogas e biopolítica na era farmacopornográfica. São Paulo: n-1 edições, 2018.

RODRIGUES, Amanda Silva. Narrativa, sofrimento e riso: algumas reflexões suscitadas por uma experiência etnográfica. Ilha, 22 (1): 128-153, 2020.

ROSE, Nikolas. Inventando nossos selfs: psicologia, poder e subjetividade. Petrópolis: Vozes, 2011.

RUSSO, Jane; VENANCIO, Ana Teresa A. Classificando as pessoas e suas perturbações: a "revolução terminológica" do DSM III. Revista Latinoamericana de Psicopatologia Fundamental, 9 (3): 460-483, 2006. 
SARTI, Cynthia. Corpo e doença no trânsito de saberes. Revista Brasileira de Ciências Sociais, 25 (74): 77-91, 2010.

VARGAS, Eduardo Viana. Uso de drogas: a alter-ação como evento. Revista de Antropologia, 49 (2): 581-623, 2006.

VELHO, Gilberto. Nobres e anjos: um estudo de tóxicos e hierarquia. 2 ed. Rio de Janeiro: FGV, 2008.

VELHO, Gilberto. Projeto e Metamorfose: Antropologia das sociedades complexas. 2 ed. Rio de Janeiro: Zahar, 1999.

VELHO, Gilberto. Uma perspectiva antropológica do uso de drogas. Jornal Brasileiro de Psiquiatria, 29 (6): 355-358, 1980.

VÍCTORA, Ceres. Sofrimento social e a corporificação do mundo: contribuições a partir da Antropologia. Revista Eletrônica de Comunicação, Informação e Inovação em Saúde, 5 (4): 3-13, 2011.

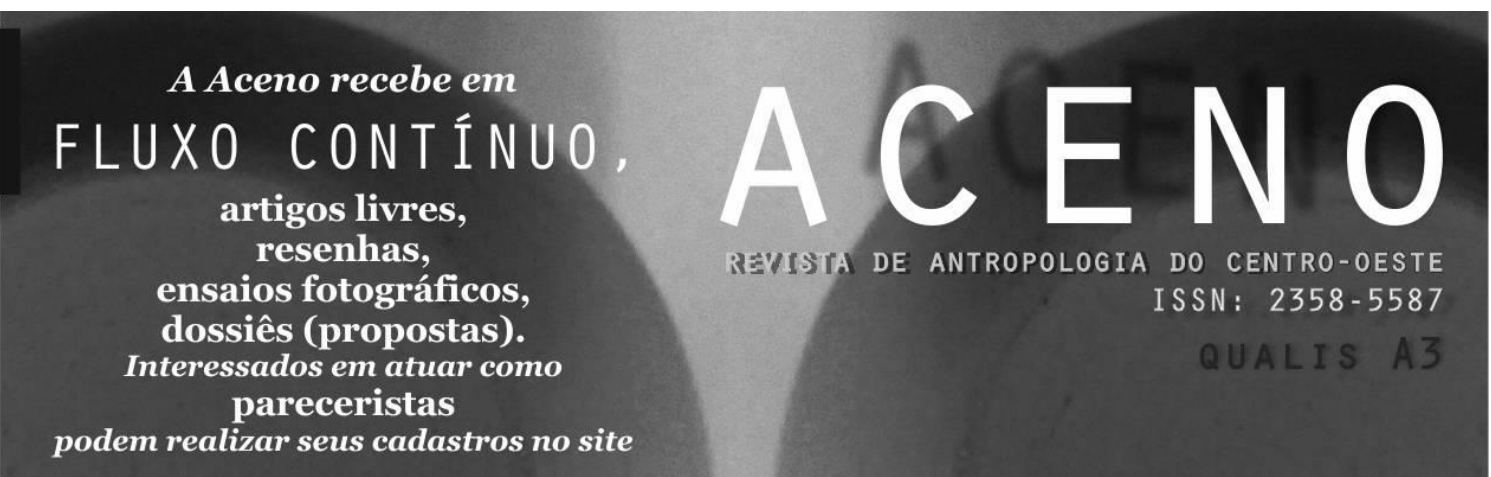

